\title{
A systematic review of tests for lymph node status in primary endometrial cancer
} Tara J Selman*1, Christopher H Mann¹, Javier Zamora² and Khalid S Khan ${ }^{1}$ Address: ${ }^{1}$ Department of Reproductive and Child Health, university of Birmingham, Birmingham Women's Hospital, Birmingham, UK and
${ }^{2}$ Clinical Biostatistics Unit, Hospital Ramón y Cajal. CIBER Epidemiologia y Salud Publica (CIBERESP). Madrid, Spain

Email: Tara J Selman* - taraselman@blueyonder.co.uk; Christopher H Mann - c.h.mann@bham.ac.uk; Javier Zamora - javier.zamora@hrc.es; Khalid S Khan - k.s.khan@bham.ac.uk

* Corresponding author

Published: 5 May 2008

BMC Women's Health 2008, 8:8 doi:10.1 186/1472-6874-8-8
Received: 28 August 2007

Accepted: 5 May 2008

This article is available from: http://www.biomedcentral.com//472-6874/8/8

(C) 2008 Selman et al; licensee BioMed Central Ltd.

This is an Open Access article distributed under the terms of the Creative Commons Attribution License (http://creativecommons.org/licenses/by/2.0), which permits unrestricted use, distribution, and reproduction in any medium, provided the original work is properly cited.

\begin{abstract}
Background: The lymph node status of a patient is a key determinate in staging, prognosis and adjuvant treatment of endometrial cancer. Despite this, the potential additional morbidity associated with lymphadenectomy makes its role controversial. This study systematically reviews the accuracy literature on sentinel node biopsy; ultra sound scanning, magnetic resonance imaging (MRI) and computer tomography (CT) for determining lymph node status in endometrial cancer.

Methods: Relevant articles were identified form MEDLINE (1966-2006), EMBASE (1980-2006), MEDION, the Cochrane library, hand searching of reference lists from primary articles and reviews, conference abstracts and contact with experts in the field. The review included 18 relevant primary studies (693 women). Data was extracted for study characteristics and quality. Bivariate random-effect model meta-analysis was used to estimate diagnostic accuracy of the various index tests.

Results: MRI (pooled positive LR 26.7, $95 \% \mathrm{Cl} 10.6$ - 67.6 and negative LR $0.2995 \% \mathrm{Cl} 0.17$ 0.49 ) and successful sentinel node biopsy (pooled positive LR I8.9 95\% Cl $6.7-53.2$ and negative LR $0.22,95 \% \mathrm{Cl} 0.1-0.48$ ) were the most accurate tests. CT was not as accurate a test (pooled positive LR $3.8,95 \% \mathrm{Cl} 2.0-7.3$ and negative LR of $0.62,95 \% \mathrm{Cl} 0.45-0.86$. There was only one study that reported the use of ultrasound scanning.

Conclusion: MRI and sentinel node biopsy have shown similar diagnostic accuracy in confirming lymph node status among women with primary endometrial cancer than CT scanning, although the comparisons made are indirect and hence subject to bias. MRI should be used in preference, in light of the ASTEC trial, because of its non invasive nature.
\end{abstract}

\section{Background}

Endometrial cancer is a cancer of the developed world. In Europe it is the most common gynaecological cancer and the fourth most common female cancer after breast, lung and colon cancer [1]. Despite the frequency of this disease the treatment of this cancer, especially in its early stage remains controversial. In 1988 FIGO changed the staging of endometrial cancer to include pelvic and paraaortic lymphadenectomy in acceptance that the lymph node status is one of the most important prognostic factors for a patient [2]. This led to large variations in practice throughout the UK and Europe. A Study of Gynaecological Oncol- 
ogists in Western Europe revealed only 24.4\% performed lymphadenectomy and that despite it's inclusion as part of FIGO staging most reserved it for specific pathological conditions [3].

Advocates for lymphadenectomy demonstrate that it allows precise determination of prognosis, accurate tailoring of adjuvant therapy, and may potentially provide a small survival advantage [4]. Others argue that routine lymphadenectomy is associated with an increased operative time averaging an extra 30 minutes, an increased risk of intraoperative complications and that lymphadenectomy is not necessary in women with good prognostic factors that are at low risk of lymph node involvement. Women with stage $1 \mathrm{a}-1 \mathrm{c}$ disease have less than $0-15 \%$ chance of lymph node metastasis.

In light of the controversy surrounding the benefits and risks of lymphadenectomy in patients with endometrial cancer there is increasing interest in minimal and non invasive techniques to determine their lymph node status. Potentially the introduction of a reliable technique could direct the most appropriate patient treatment without the unnecessary risk of lymphadenectomy. As in other cancers studies have investigated the use of imaging techniques and sentinel node biopsy, but the accuracy of these modalities has not been adequately assessed. We systematically reviewed the evidence for the accuracy of minimally invasive and non invasive tests to determine the lymph node status in women with primary endometrial cancer.

\section{Methods}

We used widely recommended methodology in the design of our protocol for the systematic review of the literature $[5,6]$.

\section{Sources}

Our search attempted to capture all the studies that reported the diagnostic accuracy of sentinel node biopsy, positron emission tomography (PET), magnetic resonance imaging (MRI), computer tomography (CT) and ultrasound scanning for the detection of lymphatic spread in primary endometrial cancer. Bibliographic databases MEDLINE (1966-2006), EMBASE, Cochrane Library (issue II, 2006) and MEDION (1980-2006) were searched without language restrictions. The search strategy used relevant medical subheadings (MeSH), text words and word variants for endometrial cancer and combined these with the terms for the index tests and lymphadenopathy (see Additional file 1). Hand searches of reference lists from primary articles and other reviews were carried out to identify manuscripts missed by electronic searching. Experts in the field were contacted for unpublished studies and conference abstracts were reviewed.

\section{Study selection and data extraction}

The selection of studies involved a two-stage process and two reviewers (TJS, CHM). The electronic searches were examined and complete manuscripts of potentially relevant citations retrieved for a final decision on inclusion based on pre-defined selection criteria. Studies were selected if they reported accuracy of the index tests, compared to histological examination of the lymph nodes (reference standard) in women with a primary presentation of endometrial cancer of any histological type or stage and allowed data extraction to create two by two tables. No language restrictions were applied. In cases of duplicate publications the most recent manuscript was selected. Final inclusion or exclusion was decided after examining the complete manuscripts. All were examined in duplicate by the two reviewers with any discrepancies resolved by a third reviewer (KSK).

A piloted data extraction form was used to collect information on study characteristics, quality and accuracy results from each of the selected manuscripts. The study characteristics extracted were the stage of disease, the index test and reference standard methodology and the setting and date of the study. Accuracy data from the studies were reordered in two by two tables. For the purpose of analysis when a manuscript reported the accuracy of more than one index test, the tests were reported on separately. Non diagnostic test results and a failure to perform the test, such as an inability to detect the sentinel node or inadequate histology were excluded from the two by two tables, but their occurrence was recorded, along with the results from the reference standard in each case, if provided.

\section{Assessment of Study Quality}

All of the manuscripts meeting the selection criteria were assessed for their methodological quality, defined as the confidence that the study design, conduct and analysis minimised biases in the estimation of test accuracy. Existing, well developed tools were used to generate items for our assessment of methodological quality [7-9], this process was again carried out in duplicate. For the population, consecutive or random recruitment of eligible women in to the study was considered ideal. Convenience sampling, such as arbitrary recruitment or non-consecutive recruitment was deemed inadequate. Prospective recruitment of patients was considered to be associated with potentially a lesser degree of bias than retrospective recruitment. The description of the population was considered ideal if the study clarified the stage of disease and the body mass index of a patient, which can affect the accuracy of techniques. We recorded the stage of disease in accordance 
with FIGO classification. The reporting of the index test was considered ideal if the study documented the test in sufficient detail to allow replication by other researchers. It was considered important for the time interval between the index test and the reference standard to be described and an interval of four or less weeks was considered suitable [10]. For the reference standard itself, a description of method of histological verification was important and it was considered preferable for the readers of the reference standard to be blind to the index test results. Information on the number of women recruited into the study and those on whom outcome data were known was sought from the manuscripts to examine partial and differential verification. Verification was considered ideal if all women originally enrolled into the study, without legitimate exclusions were included in the data analysis. We examined if withdraws from the study were explained and if uninterpretable results were reported.

The main strengths and weaknesses in respect of each of the above items for all studies included in the systematic review were tabulated. We did not attempt to collapse our assessment of quality into a score, as suggested methods have little validity and may have a tendency to obscure the strengths and weaknesses of a study rather than clarify them.

\section{Data synthesis}

From the two by two tables, sensitivity (true positive rate) and specificity (true negative rate), along with their exact confidence intervals were computed. These estimates were plotted in a ROC space to evaluate the degree of correlation between these indices. When two by two tables contained zero cells we applied a standard correction of adding 0.5 to all four cells of that table [11].

We anticipated that in common with other diagnostic reviews $[10,12,13]$ there would be heterogeneity of results amongst involved studies. We examined heterogeneity visually using forest plots of sensitivity, specificity and LRs and statistically using Cochran Q [14]. The small number of studies did not allow for detailed exploration of reasons for heterogeneity using meta regression techniques. However studies were instead divided into index test type, which in previous reviews has represented a major source of heterogeneity [16] and difference in accuracy were tested for statistical significance.

We used bivariate random-effect meta-analysis [16] to obtain summary estimates of sensitivity and specificity and other derived measures such as positive and negative likelihood ratios (LRs). LRs allow estimation of the probability of lymphatic spread with a specific test result [1719]. The bivariate model assumes that logit transformations of sensitivity and specificity are negatively correlated and follow a bivariate normal distribution. This analysis also incorporates the different precision by which sensitivity and specificity have been measured in each study. The model produces random effect estimations for the mean logit sensitivity and specificity with corresponding $95 \%$ confidence intervals, it produces also an estimation for the amount of between-study variation for sensitivity and specificity separately, and finally an estimation of the covariance between sensitivity and specificity. Confidence regions in logit-ROC space can be constructed using these estimates. The ellipse in logit-ROC space can be backtransformed to conventional scale, and plotted in ROC space giving a confidence region for the summary operating point.

Meta-DiSc version 1.4 [14] was used for initial analyses and forest plots and the PROC MIXED procedure in SAS version 8.2 for Windows (SAS Institute) was used to fit bivariate models.

\section{Results}

A total of 18 manuscripts including 693 women with primary endometrial cancer were included in the review [2037] (Figure 1). There were 19 two by two tables evaluating one of four index tests, there were no studies identified that reported the accuracy of PET. A proportion of the population $(106 / 693,15 \%)$ were included more than once in 2/19 two by two tables. Table 1 and Figure 2 summaries the salient features and quality of each of the studies. It is evident that there was a wide variation and numerous deficiencies in the methodological quality of the included studies.

Figure 3 show Forrest plots with sensitivities and specificities of individual studies according to index test. Table 2 shows pooled sensitivities and specificities for the various index tests estimated by the bivariate analysis from which we derived other measures such as positive and negative likelihood ratios. Figure 4 shows the summary operating estimates for the various index tests with corresponding confidence ellipses. For each of the index tests variation in sensitivity was much greater than specificity. MRI was the most accurate index test while successful sentinel node had similar results (Table 2). P-values of tests for comparison between the three main diagnostic modalities are shown in Table 2. CT was much less accurate in detection of lymphatic spread (Table 2). There was only one study that reported the accuracy of ultrasound scanning the results of which were positive LR 50.3 and a negative LR 0.67 , the presence of only one study makes it difficult to draw a conclusion concerning this technique, other than to note the sensitivity of the test (33\%) was poor. The failure rate to detect the sentinel node ranged from $6.6 \%(1 /$ 16 patients) to $100 \%$. 


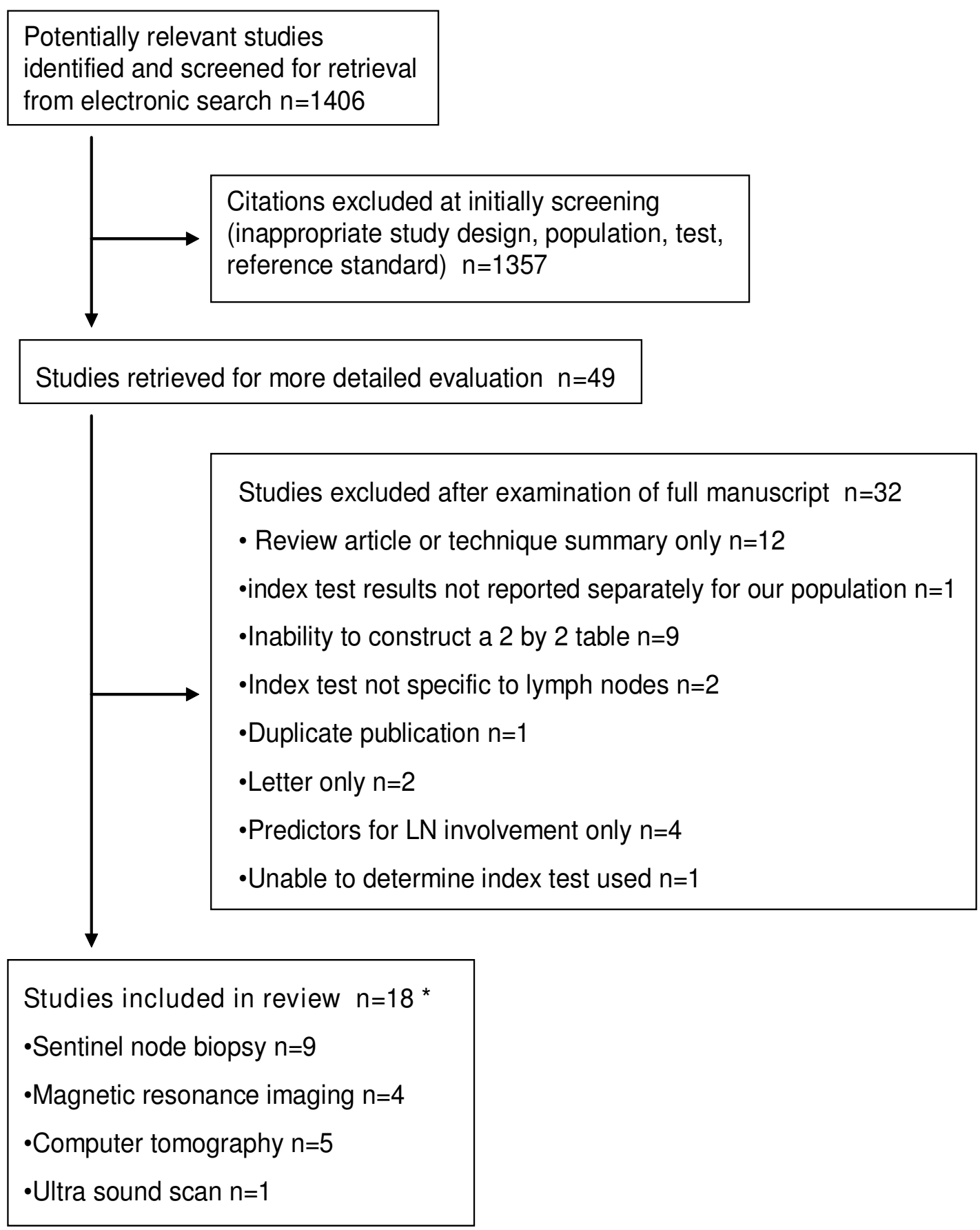

* One study evaluated more than one test

The reference list for excluded studies is available from the corresponding author

Figure I

Study selection process for systematic review of literature on accuracy of tests for lymph node metastasis in endometrial cancer. 


\section{Quality Items}

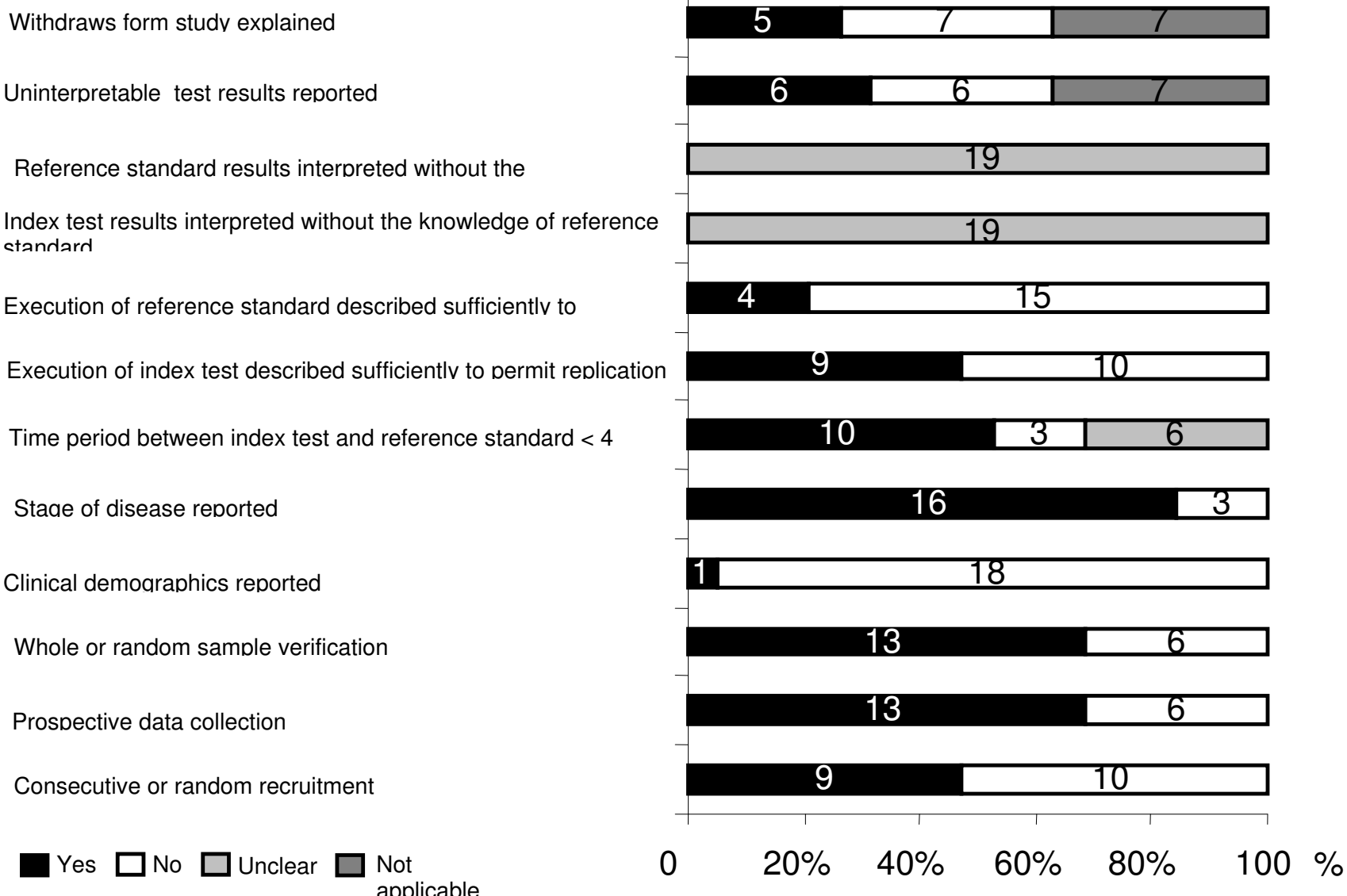

Figure 2

The quality of studies included in systematic review of literature on accuracy of tests for lymph node metastasis in endometrial cancer. Stacked bar chart used. Numbers in bars indicate number of studies.

\section{Discussion}

Our review showed that MRI and successful sentinel node biopsy (sentinel node biopsy has a variable failure rate) were the most accurate tests for predicting the lymph node status of women with primary endometrial cancer. Other tests were poor in accuracy. These results must be interpreted with caution as the quality of studies available for review was variable, with many of poor methodological quality that may result in the introduction of bias. This review show an urgent need for the further high quality primary studies that include the use of PET scanning as an alternative test which may be beneficial.

This review provides a robust summary of the available evidence to date and an example of the methodology required to perform a review of diagnostic test accuracy. We performed an extensive search for studies and used well developed methods for quality assessment. The deficiencies in quality made explicit by our review should help improve further research in this area [7]. It is imperative that the new STARD and QUADAS guidelines are followed in the undertaking of such studies so that our inference in the future can be based on high quality review, reducing heterogeneity and the risk of bias. Another criticism of our approach might be that in light of the unexplained heterogeneity in the results, meta analysis should perhaps have been avoided. We also accept that we are combing results of tests over a wide time scale, where the accuracy of the technique may have improved. Also that the comparison of tests is an indirect one and hence subject to bias, especially as there is a wide variation in the spectrum of diseases that the different tests are used in.

Our study shows that based on the currently available evidence MRI is the most accurate tool to determine the lymph node status of patients. It has the advantage of also guiding the surgeon as to the depth of myometrial inva- 


\begin{tabular}{|c|c|c|c|c|c|}
\hline $\begin{array}{l}\text { Author and } \\
\text { Index Test }\end{array}$ & Year & Population & Setting & Index test and failure rate & $\begin{array}{l}\text { Reference Standard } \\
\text { Histological method }\end{array}$ \\
\hline \multicolumn{6}{|l|}{ SN } \\
\hline Burke TW & 1996 & $\begin{array}{l}15 \text { women recruited } 15 \text { women had index test and reference standard } \\
\text { Stage: not stated Pelvic and paraaortic selective lymphadenectomy Open } \\
\text { surgery }\end{array}$ & $\begin{array}{l}\text { Hospital - Not stated Country - USA Dates } \\
\text { - not stated }\end{array}$ & $\begin{array}{l}\text { SN biopsy using } 3 \mathrm{mls} \text { blue dye injected into subserosal myometrium } \\
\text { I women unable to identify SN, positive lymph node status }\end{array}$ & $\begin{array}{l}\text { Histological method not } \\
\text { stated }\end{array}$ \\
\hline Echt M & 1999 & $\begin{array}{l}8 \text { women recruited } 8 \text { women had index test and } 7 \text { reference standard } \\
\text { Advanced disease prevented lymphadenectomy Stage:IB Pelvic and } \\
\text { paraaortic lymphadenectomy Open surgery }\end{array}$ & $\begin{array}{l}\text { Hospital - Alton Ochsner Medical } \\
\text { Foundation and University of South Florida } \\
\text { Collage of Medicine Dates - 01/01/1993 - } \\
31 / 03 / 1995\end{array}$ & $\begin{array}{l}\text { SN biopsy using } 2 \mathrm{mls} \text { blue dye injected into uterine funds In all } 7 \\
\text { women unable to identify SN, I women positive histology }\end{array}$ & $\begin{array}{l}\text { Histological method not } \\
\text { stated }\end{array}$ \\
\hline Holub Z & 2001 & $\begin{array}{l}8 \text { women recruited } 8 \text { women had index test and reference standard } \\
\text { Stage:IA-I, IB-5, IC-I, IIIC-I Pelvic lymphadenectomy Laparoscopic surgery }\end{array}$ & $\begin{array}{l}\text { Hospital - Not stated Country - Czech } \\
\text { Republic Dates - 0I/200 - I I/2000 }\end{array}$ & $\begin{array}{l}\text { SN biopsy using } 2 \mathrm{mls} \text { blue dye injected into subserosal myometrium } \\
3 \text { women unable to identify SN, all women histology negative }\end{array}$ & $\begin{array}{l}\text { Histological method not } \\
\text { stated }\end{array}$ \\
\hline Niikura $\mathrm{H}$ & 2003 & $\begin{array}{l}28 \text { women recruited } 28 \text { women had index test and reference standard } \\
\text { Stage: IA-7, IB-II, IIA-2, IIB-I, IIIA-I, IIIC-2 Pelvic and paraaortic } \\
\text { lymphadenectomy Open surgery }\end{array}$ & $\begin{array}{l}\text { Hospital - Tohoku University School of } \\
\text { Medicine Country - Japan Dates - } 06 / 01 \text { - } \\
01 / 03\end{array}$ & $\begin{array}{l}\text { SN biopsy using } 70 \mathrm{MBq} \text { technetium- } 99 \mathrm{~m} \text { colloidal albumin injected } \\
\text { hysteroscopically into endomertium } 5 \text { women unable to identify a SN, } \\
\text { I women positive histology }\end{array}$ & $\begin{array}{l}\mathrm{H} \text { and } \mathrm{E} \text { staining and } \\
\text { mmunohistochemistry }\end{array}$ \\
\hline Pelosi E & 2003 & $\begin{array}{l}16 \text { women recruited } 16 \text { women had index test and reference standard } \\
\text { Stage: Ib- } 16 \text { Pelvic lymphadenectomy Laparoscopic surgery }\end{array}$ & $\begin{array}{l}\text { Hospital - Not stated Country - Italy Dates } \\
-02 / 02-04 / 02\end{array}$ & $\begin{array}{l}\text { SN biopsy using } 37 \mathrm{MBq} \text { technetium- } 99 \mathrm{~m} \text { colloidal albumin and } 4 \mathrm{ml} \\
\text { blue dye injected into the cervix I women unable to identify SN, } \\
\text { negative lymph node status }\end{array}$ & $\begin{array}{l}\mathrm{H} \text { and } \mathrm{E} \text { staining and } \\
\text { immunohistochemistry }\end{array}$ \\
\hline Raspagliesi F & 2003 & $\begin{array}{l}18 \text { women recruited } 18 \text { women had index test } 14 \text { women had reference } \\
\text { standard4 excluded, } 2 \text { due to disease stageStage IA-4, IB-9, IIIA-I, IIIC- } \\
\text { 4Pelvic lymphadenectomy in all women, paraaortic only if deemed } \\
\text { necessaryOpen surgery }\end{array}$ & $\begin{array}{l}\text { Hospital - Not statedCountry - ItalyDates - } \\
\text { Not stated }\end{array}$ & $\begin{array}{l}\text { SN biopsy using III MBq technetium-99 m colloidal albumin injected } \\
\text { hysteroscopically into sub endomertium }\end{array}$ & $\mathrm{H}$ and $\mathrm{E}$ staining \\
\hline Fersis $\mathrm{N}$ & 2003 & $\begin{array}{l}10 \text { Women recruited } 10 \text { women had index test and reference standard } \\
\text { Stage : Ib pelvic }+ \text { - paraaortic lymphadenectomy Open surgery }\end{array}$ & $\begin{array}{l}\text { Hospital - Not stated Country - Germany } \\
\text { Dates - Not stated }\end{array}$ & $\begin{array}{l}\text { SN biopsy using } 40-100 \mathrm{MBq} \text { technetium- } 99 \mathrm{~m} \text { colloidal albumin } \\
\text { injected hysteroscopically into tumour } 3 \text { patients unable to identify } \\
\text { SN, patient's lymph node status was negative }\end{array}$ & $\begin{array}{l}\text { Histological method not } \\
\text { stated }\end{array}$ \\
\hline Holub Z & 2004 & $\begin{array}{l}25 \text { women recruited } 25 \text { women had index test and reference standard } \\
\text { Stage: not stated Pelvic lymphadenectomy (yes patent had sampling only) } \\
\text { Laparoscopic surgery }\end{array}$ & $\begin{array}{l}\text { Hospital - Not stated Country-Czech } \\
\text { Republic Dates - 02/00 - 08/03 }\end{array}$ & $\begin{array}{l}\text { SN using } 5 \mathrm{ml} \text { blue dye injected into cervix and uterine fundus } 4 \\
\text { patients unable to identify SN, patients lymph node status was } \\
\text { negative }\end{array}$ & $\begin{array}{l}\text { Histological method not } \\
\text { stated }\end{array}$ \\
\hline Lelievre L & 2004 & $\begin{array}{l}12 \text { women recruited } 12 \text { women had index test and reference standard } \\
\text { Stage: Ib-2, Ic-5, Ila-I, Ilb-I, IIlc-3 Pelvic lymphadenectomy Laparoscopic } \\
\text { surgery }\end{array}$ & $\begin{array}{l}\text { Hospital - Not stated Country - France } \\
\text { Dates } 01 / 02-12 / 02\end{array}$ & $\begin{array}{l}\text { SN biopsy using } 120 \mathrm{MBq} \text { technetium- } 99 \mathrm{~m} \text { colloidal albumin injected } \\
\text { in to the cervix and } 2 \mathrm{mls} \text { blue dye injected into the cervix } 1 \mathrm{I} \text { patients } \\
\text { had } \mathrm{SN} \text { identified using combined technique, } 10 \text { using technetium- } 99 \\
\mathrm{~m} \text { alone and } 9 \text { using blue dye alone }\end{array}$ & $\begin{array}{l}H \text { and E staining and } \\
\text { immunohistochemistry }\end{array}$ \\
\hline \multicolumn{6}{|c|}{ 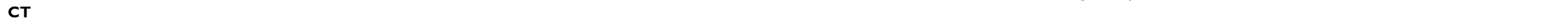 } \\
\hline Balfe DM & 1983 & $\begin{array}{l}61 \text { women recruited } 18 \text { women had index test and reference standard } 43 \\
\text { women excluded without explanation Stage: not stated Pelvic and } \\
\text { paraaortic lymphadenectomy Open surgery }\end{array}$ & $\begin{array}{l}\text { Hospital - Mallinckrodt Institute of } \\
\text { Radiology Country - USA Dates - } 07 / 76 \text { - } \\
07 / 8 \text { I }\end{array}$ & $\begin{array}{l}\text { CT using EMI CT500S and EMI } 7070 \text { 3s scanners Lymph nodes > } 10 \\
\text { mm abnormal }\end{array}$ & $\begin{array}{l}\text { Histological method not } \\
\text { stated }\end{array}$ \\
\hline Varpula MJ & 1993 & $\begin{array}{l}47 \text { women recruited } 47 \text { women had index test } 43 \text { women had index test and } \\
\text { reference standard, } 4 \text { women excluded as suitable for } d x t \text { onlyStage: I-36, II- } \\
7 \text { Pelvic and paraaortic unilateral and bilateral clearance and samplingOpen } \\
\text { surgery }\end{array}$ & $\begin{array}{l}\text { Hospital - Not statedCountry - } \\
\text { FinlandDates - 05/87-05/90 }\end{array}$ & $\begin{array}{l}\text { CT scan using Siemans Somatom CR/General Electric } 9800 \\
\text { scannerslymph nodes }>10 \mathrm{~mm} \text { abnormal }\end{array}$ & $\begin{array}{l}\text { Histological method not } \\
\text { stated }\end{array}$ \\
\hline La Fianza A & 1997 & $\begin{array}{l}\text { I25 women recruited I } 25 \text { women index test and reference standard Stage: } \\
\text { I-125, II- I2, III-8 Pelvic lymphadenectomy Open surgery }\end{array}$ & $\begin{array}{l}\text { Hospital - Not stated Country - Italy Dates } \\
-01 / 1996-09 / 1993\end{array}$ & $\begin{array}{l}\text { CT using III generation Somatom 2, Somatome Plus and Siemens } \\
\text { scanner }\end{array}$ & $\begin{array}{l}\text { Histological method not } \\
\text { stated }\end{array}$ \\
\hline Conner JP & 2000 & $\begin{array}{l}702 \text { women were eligible, } 210 \text { excluded follow up at another centre, } \\
\text { secondary malignancy or no surgery planned } 487 \text { women excluded as no } \\
\text { CT } 75 \text { women had index test } 56 \text { women had reference standard, } 6 \text { had no } \\
\text { lymphadenectomy due to index test results, I } 3 \text { no explanation Stage : I-350, } \\
\text { II- } 73 \text {, III- } 49 \text {, IV-20 Pelvic and paraaortic lymph node sampling Open surgery }\end{array}$ & $\begin{array}{l}\text { Hospital - University of lowa Hospital and } \\
\text { Clinics Country - USA Dates - } 1979-1993\end{array}$ & CT scanner model not stated & $\begin{array}{l}\text { Histological method not } \\
\text { stated }\end{array}$ \\
\hline Zerbe M & 2000 & $\begin{array}{l}54 \text { women recruited } 54 \text { women index test } 36 \text { women reference standard, } \\
\text { no explanation for exclusion Stage I-III Lymph node type not stated Surgery } \\
\text { type not stated }\end{array}$ & $\begin{array}{l}\text { Hospital - Baltimore Medical Centre } \\
\text { Country - USA Dates - 01/90 - 12/98 }\end{array}$ & $\begin{array}{l}\text { CT scanner model not stated No definition for lymph node } \\
\text { abnormality }\end{array}$ & $\begin{array}{l}\text { Histological method not } \\
\text { stated }\end{array}$ \\
\hline \multicolumn{6}{|c|}{ 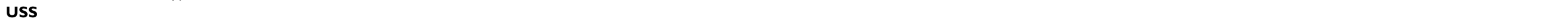 } \\
\hline Sawicki W & 2003 & $\begin{array}{l}90 \text { women recruited } 90 \text { women had index test and reference standardStage } \\
\text { - not statedlymph node type not statedSurgery type, not stated }\end{array}$ & $\begin{array}{l}\text { Hospital - Not statedCountry - } \\
\text { PolandDates - Not stated }\end{array}$ & $\begin{array}{l}\text { USS either abdominal or transvaginal using Siemens Sonoline Versu } \\
\text { Prox with a } 6.5-7.5 \mathrm{MHZ} \text { probe for transvaginal and } 3.5 \mathrm{MHZ} \text { probe } \\
\text { for abdominal definition for lymph node abnormality }\end{array}$ & $\begin{array}{l}\text { Histological method not } \\
\text { stated }\end{array}$ \\
\hline \multicolumn{6}{|c|}{$\mathrm{C}$} \\
\hline Hricak H & 1991 & $\begin{array}{l}20 \text { women recruited } 20 \text { women had the index test and reference standard } \\
\text { Stage: }|-16,| I-1,|I|-3 \text { Pelvic lymph node sampling Open surgery }\end{array}$ & $\begin{array}{l}\text { Hospital-Not stated Country-USA Dates } \\
-01 / 02 / 89-01 / 12 / 89\end{array}$ & $\begin{array}{l}\text { MRI using I.5T Sigma and I.5T Magnetom scanner lymph nodes > } 10 \\
\text { mm abnormal }\end{array}$ & $\begin{array}{l}\text { Histological method not } \\
\text { stated }\end{array}$ \\
\hline Varpula MJ & 1993 & $\begin{array}{l}46 \text { women recruited } 46 \text { women had index test } 43 \text { women had the index } \\
\text { test and reference standard, } 3 \text { excluded as suitable for DXT only Stage: I- } \\
36 \text {, II-7 Pelvic and paraaortic unilateral and bilateral clearance and sampling } \\
\text { Open surgery }\end{array}$ & $\begin{array}{l}\text { Hospital - Not stated Country - Finland } \\
\text { Dates - 05/87-05/90 }\end{array}$ & MRI using $<0.05 T$ Acut scanner Lymph nodes $>10 \mathrm{~mm}$ abnormal & $\begin{array}{l}\text { Histological method not } \\
\text { stated }\end{array}$ \\
\hline Taieb $S$ & 2002 & $\begin{array}{l}86 \text { women recruited } 86 \text { women had index test and reference standard } \\
\text { Stage: Ia-24, Ib-26, Ic-14, Ila-2, lib-2, Illc-15, IVa-2, IVb-I Pelvic and } \\
\text { paraaortic lymphadenectomy Open surgery }\end{array}$ & $\begin{array}{l}\text { Hospital - Not stated Country - France } \\
\text { Dates - 01/97-03/02 }\end{array}$ & MRI scanner type not stated & $\begin{array}{l}\text { Histological method not } \\
\text { stated }\end{array}$ \\
\hline Manfredi R & 2004 & $\begin{array}{l}37 \text { women recruited } 37 \text { women had index test } 21 \text { women had reference } \\
\text { standard, } 16 \text { women excluded as no lymph nodes were palpable Stage: la-2, } \\
\text { lb-20, Ic- } 15 \text { Pelvic lymph node sampling in } 11 \text {, pelvic and paraaortic } \\
\text { lymphadenectomy in } 10 \text { Open surgery }\end{array}$ & $\begin{array}{l}\text { Hospital - Not stated Country - Italy Dates } \\
-06 / 97-02-01\end{array}$ & $\begin{array}{l}\text { MRI using } 1.5 T \text { Echospeed, GE medical System scanner Lymph nodes } \\
\text { abnormal > } 10 \mathrm{~mm}\end{array}$ & $\begin{array}{l}\text { Histological method not } \\
\text { stated }\end{array}$ \\
\hline
\end{tabular}



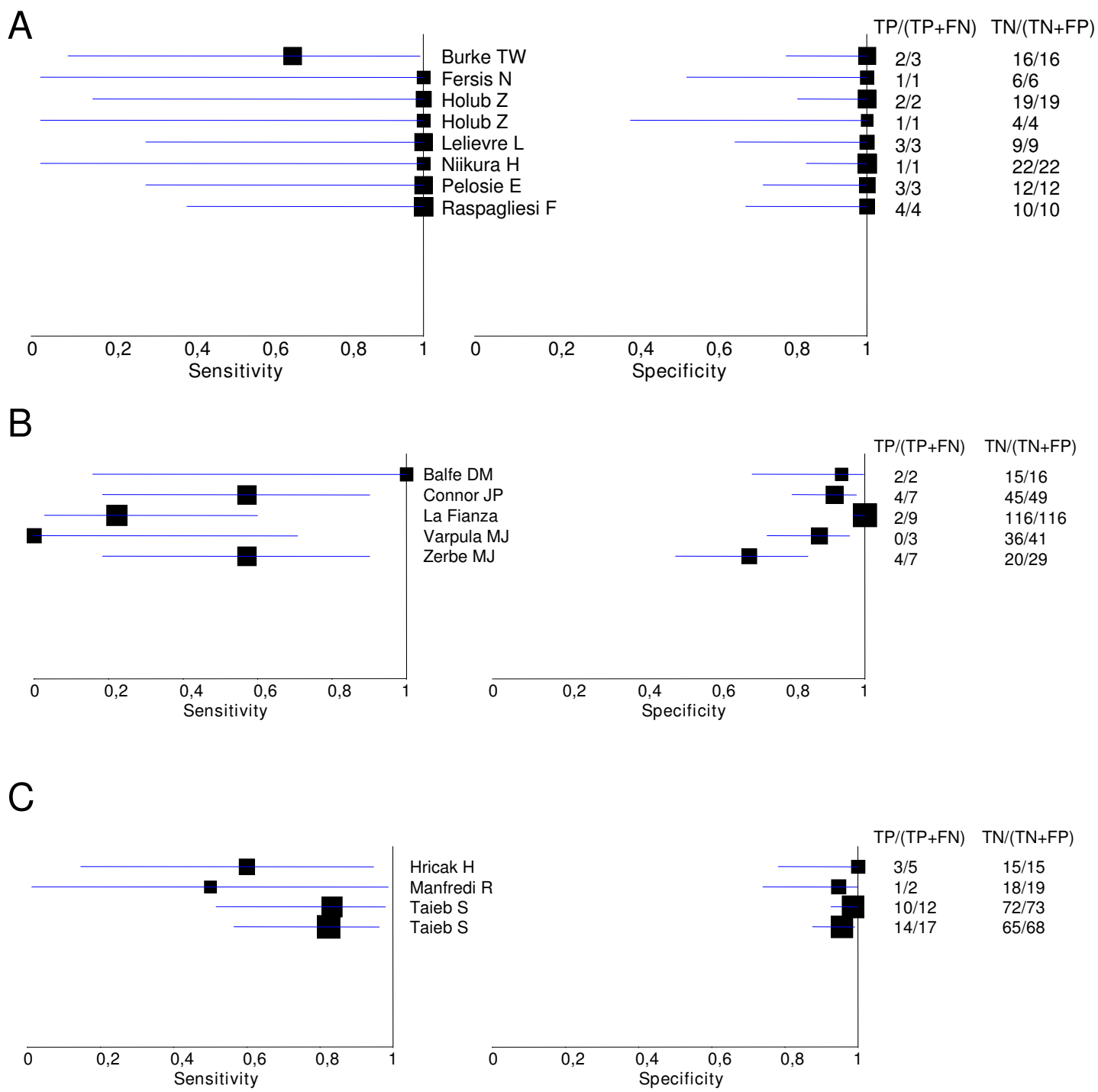

Figure 3

Forrest plots of sensitivity and specificity for the various index tests. A. Sentinel node biopsy B. CT scanning C. MRI.

sion and potential treatment required. Reviews of test accuracy for lymphatic spread in other gynaecological cancers have shown sentinel node biopsy to be the most accurate test, as have studies in other cancers [15]. However this did not appear to be the case for endometrial cancer as MRI was marginally more accurate, although this was not a statistically significant increase in accuracy over sentinel node biopsy. There was a large variation in the ability to detect the sentinel node. Although this usually occurred in a small percentage of patients in the studies, one study was unable to detect the node in any of its patients [21]. This may have been due the different technique used and the reliance on only blue dye to detect the node (Table I).
The debate regarding the necessity of lymphadenectomy in these patients led to the Medical Research Council funded ASTEC (a study in the treatment of endometrial cancer) trial. One of the study's primary aims is to assess the benefit, or otherwise of pelvic lymphadenectomy in patients where disease is thought to be confined to the corpus. Recruitment for this trial had now closed and the preliminary results were presented at European Society of Gynaecological Oncology in 2005. They suggested that there was no benefit for survival or prevention of recurrence in performing lymphadenectomy for early stage endometrial cancer. If this is confirmed in the final publication of the trial then it adds further importance to the use of a non invasive assessment of lymph node status 
Table 2: Summary estimates for sensitivity, specificity and positive and negative likelihood ratios from the bivariate model.

\begin{tabular}{lcccc}
\hline Index test & Mean sensitivity $(95 \% \mathrm{Cl})$ & Mean specificity $(95 \% \mathrm{Cl})$ & Positive likelihood ratio $(95 \% \mathrm{Cl})$ & Negative likelihood ratio $(95 \% \mathrm{Cl})$ \\
\hline Sentinel Node $(\mathrm{SN})$ & $0.79(0.58$ to 0.91$)$ & $0.96(0.89$ to 0.99$)$ & $18.88(6.70$ to 53.24$)$ & $0.22(0.10$ to 0.48$)$ \\
CT scan & $0.45(0.28$ to 0.64$)$ & $0.88(0.78$ to 0.94$)$ & $3.81(2.00$ to 7.28$)$ & $0.62(0.45$ to 0.86$)$ \\
MRI & $0.72(0.55$ to 0.85$)$ & $0.97(0.93$ to 0.99$)$ & $26.72(10.56$ to 67.64$)$ & $0.29(0.17$ to 0.49$)$
\end{tabular}

Sensitivity: $\mathrm{p}$-value $S N$ vs $C T=0.018, \mathrm{p}$-value $S N$ vs $M R I=0.546, p$-value $C T$ vs $M R I=0.039$

Specificity: $\mathrm{p}$-value $S N$ vs $C T=0.095, \mathrm{p}$-value $S N$ vs $M R I=0.546, p$-value $C T$ vs $M R I=0.014$

which would allow a decision to be made on the requirement of adjuvant surgery, which in light of this trial will be the only potential benefit of lymphadenectomy.

\section{Conclusion}

Independent of the results of ASTEC there are still benefits in accurately being able to use a non or minimally invasive technique to predict the lymph node status of patients with primary endometrial cancer. This systematic review of the available evidence suggests that MRI is the most accurate method to do this, however one should be cautious in interpreting the results in view of the number and heterogeneity of the studies available and the large confidence intervals of results. Further high quality studies are required to look at the real potential both of this and other imaging modalities such as PET.

\section{Competing interests}

The authors declare that they have no competing interests.

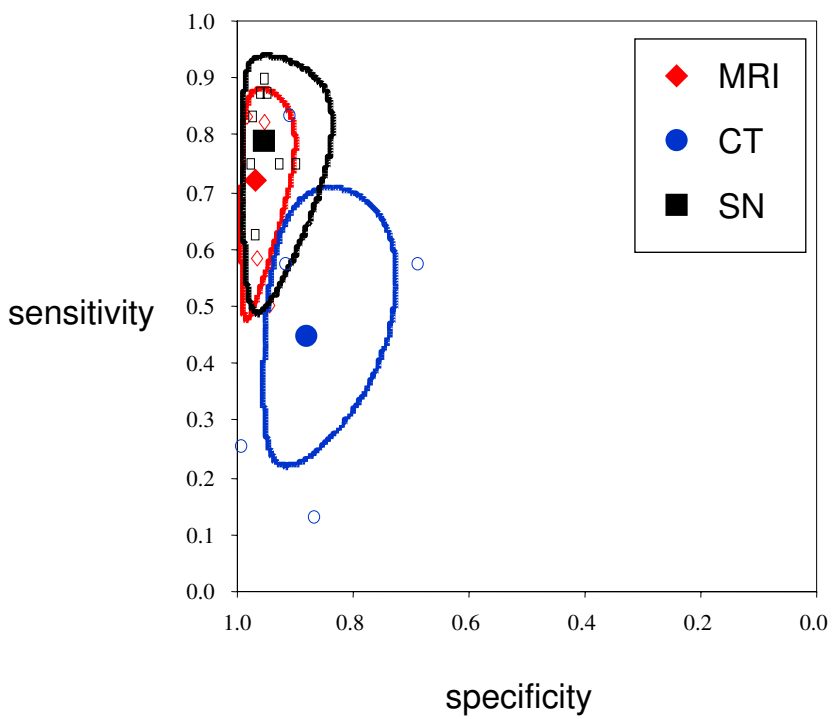

\section{Figure 4}

Bivariate summary estimates of sensitivity and specificity for each of the three index tests and the corresponding $95 \%$ confidence ellipse around these mean values. Open symbols are individual studies.

\section{Authors' contributions}

TS participated in the development of the research design and the search strategy essential for systematic review, in the data analysis and interpretation of the data, in writing the first draft and the critical reading there after and approved the final version. CM participated in the development of the research question, in the data extraction and interpretation and the critical reading of the manuscript and approved the final version. JZ participated in the development of the research strategy, in writing a computer program used in the research, in the data analysis and interpretation, in providing essential statistical and methodological advice and in the critically reading of the manuscript and approved the final version. KK participated in the development of the research design and the search strategy essential for systematic review, in the data analysis and interpretation of the data, in surmounting problems that arouse, in providing essential methodological and statistical advice and in the critical reading of the manuscript and approved the final version.

\section{Additional material}

\section{Additional file 1}

Search strategy. The data provided shows the search strategy used in the systematic review of tests for lymph node status in primary endometrial cancer.

Click here for file

[http://www.biomedcentral.com/content/supplementary/14726874-8-8-S1.doc]

\section{Acknowledgements}

MRC RCOG clinical training fellowship held by Miss Tara Selman financed cost incurred in obtaining original manuscripts.

\section{References}

I. Amant F, Moeman P, Neven P, Timmerman D, Limbergen E, Vergot I: Endometrial cancer. Lancet 2005, 366:49I-505.

2. Chee IJ, Ho TH, Tay EH, Low JIH, Yam KL: Endometrioid Adenocarcinoma of the Uterus: Surgico-Pathological Correlations and Role of Pelvic Lymphadenectomy. Annals of the Academy of Medicine, Singapore 2003, 32(5):670-5.

3. Maggino T, Romagnolo C, Zola P, Sartori E, Landoni F, Gadducci A: An analysis of approaches to the treatment of endometrial cancer in Western Europe: A CTF study. European Journal of Cancer 1995, 3 I (12): 1993-7. 
4. Fanning J, Firestein S: Prospective evaluation of the morbidity of complete lymphadenectomy in endometrial cancer. International Journal of Gynecological Cancer 1998, 8(4):270-3.

5. Khan KS, Dinnes J, Kleijnen J: Systematic reviews to evaluate diagnostic tests. European Journal of Obstet Gynecol Reprod biol 200 I, 95:6-II.

6. Deeks J: Systematic reviews of evaluations of diagnostic and screening tests. In Systematic Reviews Health Care: Meta-Analysis in Context Edited by: Egger M, Smith G, Altman D. London: BMJ Books; 2001 .

7. Selman TJ, Khan KS, Mann $\mathrm{CH}$ : An evidence-based approach to test accuracy studies in gynaecologic oncology: the 'STARD' checklist. Gynecologic Oncology 2005, 96(3):575-8.

8. Lijmer J, Mol B, Heisterkamp S, Bonsel G, Prins M: Emperical evidence of design-related bias in studies of diagnostic tests. JAMA 1999, 282:106I-6.

9. Whiting P, Rutjes A, Reitsma J, Kleijnen J: The development of QUADAS : a tool for the quality assessment of studies of diagnostic accuracy included ijn systematic reviews. BMC Med Res Methodology 2003, 3(I):4I.

10. Clark TJ, Mann CH, Shah N, Khan KS, Song F, Gupta JK: Evaluation of outpatient hysteroscopy and ultrasonography in the diagnosis of endometrial disease. Obstet Gynecol 2002, 99: I001-7.

II. Sankey S, Weistfiels L, Fine M, Kapoor W: An assessment of the use of the continuity correction for sparse data in meta anlysis. Commun Stat Simulation Computation 1996, 25:103 I-56.

12. Scheidler J, Hricak H, Yu KK, Subak L, Segal MR: Radiological evaluation of lymph node metastases in patients with cervical cancer. A meta-analysis. JAMA 1997, 278(I3): I096-I0I.

13. Selman TJ, Luesley DM, Acheson N, Khan KS, Mann CH: A systematic review of the accuracy of diagnostic tests for inguinal lymph node status in vulvar cancer. Gynecologic Oncology 2005, 99(I):206-14.

14. Zamora J, Abraira V, Muriel A, Khan KS, Coomarasamy A: MetaDiSc: a software for meta-analysis of test accuracy data. $B M C$ Medical Research Methodology 2006, 6:31.

15. Selman TJ, Luesley DM, Acheson N, Khan KS, Mann CH: A systematic review of the accuracy of diagnostic tests for inguinal lymph node status in vulvar cancer. Gynecologic Oncology 2005, 99(I):206-14.

16. Reitsma JB, Glas AS, Rutjes AW, Scholten RJ, Bossuyt PM, Zwinderman $\mathrm{AH}$ : Bivariate analysis of sensitivity and specificity produces informative summary measures in diagnostic reviews. J Clin Epidemiol 2005, 58( I 0):982-90.

I7. Deeks J, Morris J: Evaluation diagnostic tests. Baillieres Clinical Obstetrics \& Gynaecology 1996, 10:613-30.

18. Jaeschke R, Guyatt G, Sackett D: Users' guide to the medical literature, III: how to use an article about a diagnostic test, $B$. JAMA 1994, 27 I:703-7.

19. Greenhalgh T: How to read a paper. Papers that report diagnostic or screening tests. $B M]$ 1997, 3( I 5):540-543.

20. Burke TW, Levenback C, Tornos C, Morris M, Wharton JT, Gershenson DM: Intraabdominal lymphatic mapping to direct selective pelvic and paraaortic lymphadenectomy in women with high-risk endometrial cancer: results of a pilot study. Gynecologic Oncology 1996, 62(2):169-73.

2I. Echt ML, Finan MA, Hoffman MS, Kline RC, Roberts WS, Fiorica JV: Detection of sentinel lymph nodes with lymphazurin in cervical, uterine, and vulvar malignancies. Southern Medical Journal 1999, 92(2):204-8.

22. Holub Z, Kliment L, Lukac J, Voracek J: Laparoscopically-assisted intraoperative lymphatic mapping in endometrial cancer: preliminary results. European Journal of Gynaecological Oncology 2001, 22(2): I| |8-2|.

23. Niikura H, Okamura C, Utsunomiya H, Yoshinaga $K$, Akahira J, Ito $K$ Yaegashi N: Sentinel lymph node detection in patients with endometrial cancer. Gynecologic Oncology 2004, 92(2):669-74.

24. Pelosi E, Arena V, Baudino B, Bello M, Giusti M, Gargiulo T, Palladin $D$, Bisi G: Pre-operative lymphatic mapping and intra-operative sentinel lymph node detection in early stage endometrial cancer. Nuclear Medicine Communications 2003, 24(9):971-5.

25. Raspagliesi F, Ditto A, Kusamura S, Fontanelli R, Vecchione F, Maccauro $M$, Solima $E$ : Hysteroscopic injection of tracers in sentinel node detection of endometrial cancer: a feasibility study. American Journal of Obstetrics \& Gynecology 2004, I 9 I (2):435-9.
26. Fersis N, Gruber I, Relakis K, Friedrich M, Becker S, Wallwiener D: Sentinel node identification and intraoperative lymphatic mapping. First results of a pilot study in patients with endometrial cancer. European Journal of Gynaecological Oncology 2004, 25(3):339-42.

27. Holub Z, Jabor A, Lukac J, Kliment L: Laparoscopic detection of sentinel lymph nodes using blue dye in women with cervical and endometrial cancer. Medical Science Monitor 2004, I0:CR587-CR59I.

28. Lelievre L, Camatte S, Frere-Belda MA, Kerrou K, Froissart M, Taurelle $R$, vilde $F$, Lecuru F: Sentinel lymph node biopsy in cervix and corpus uteri cancers. International Journal of Gynecological Cancer 2004, I 4(2):27I-8.

29. Balfe DM, Van DJ, Lee JK, Weyman PJ, McClennan BL: Computed tomography in malignant endometrial neoplasms. Journal of Computer Assisted Tomography 1983, 7(4):677-8I.

30. Varpula MJ, Klemi PJ: Staging of uterine endometrial carcinoma with ultra-low field (0.02 T) MRI: A comparative study with CT. Journal of Computer Assisted Tomography 1993, I 7(4):64I-7.

3I. La Fianza A, Di Maggio EM, Preda L, Coscia D, Tateo S, Campani R Clinical usefulness of $C T$ in the treatment of stage I endometrial carcinoma. Radiologia Medica 1997, 93(5):567-7I.

32. Zerbe MJ, Bristow R, Grumbine FC, Montz FJ: Inability of preoperative computed tomography scans to accurately predict the extent of myometrial invasion and extracorporal spread in endometrial cancer. Gynecologic Oncology 2000, 78(I):67-70.

33. Sawicki W, Spiewankiewicz B, Stelmachow J, Cendrowski K: The value of ultrasonography in preoperative assessment of selected prognostic factors in endometrial cancer. European Journal of Gynaecological Oncology 2003, 24(3-4):293-8.

34. Taieb S, Ceugnart L, Leblanc E, Chevalier A, Cabaret V, Querleu D $M R$ imaging of endometrial carcinoma: role and limits. Bulletin du Cancer 2002, 89( I I):963-8.

35. Manfredi R, Mirk P, Maresca G, Margariti PA, Testa A, Zannoni GF, Giodano D, Scambia G, Marano P: Local-regional staging of endometrial carcinoma: role of MR imaging in surgical planning. Radiology 2004, 23 I (2):372-8.

36. Connor JP, Andrews JI, Anderson B, Buller RE: Computed tomography in endometrial carcinoma. Obstetrics \& Gynecology 2000 , 95(5):692-6.

37. Hricak H, Hamm B, Semelka RC, Cann CE, Nauert T, Secaf E, Stem JK, Wof KJ: Carcinoma of the uterus: use of gadopentetate dimeglumine in MR imaging. Radiology I991, I8I(I):95-106.

\section{Pre-publication history}

The pre-publication history for this paper can be accessed here:

http://www.biomedcentral.com/1472-6874/8/8/prepub

Publish with Biomed Central and every scientist can read your work free of charge

"BioMed Central will be the most significant development for disseminating the results of biomedical research in our lifetime. "

Sir Paul Nurse, Cancer Research UK

Your research papers will be:

- available free of charge to the entire biomedical community

- peer reviewed and published immediately upon acceptance

- cited in PubMed and archived on PubMed Central

- yours - you keep the copyright 